\title{
Associations of tumor regression grade with outcomes in patients with locally advanced rectal cancer treated with preoperative two-week course of radiotherapy
}

\author{
Yong-Heng Li ${ }^{1, *}$, Jin-Luan Lii,*, Xiang-Gao Zhu ${ }^{1}$, Jun-Yan He ${ }^{3}$, Li-Mei Lin ${ }^{4}$, Xiao-Yi \\ Lin $^{5}$, Li-Rui Tang ${ }^{2}$ and Yong Cai ${ }^{1}$ \\ ${ }^{1}$ Department of Radiation Oncology, Key Laboratory of Carcinogenesis and Translational Research (Ministry of Education / \\ Beijing), Peking University Cancer Hospital \& Institute, Beijing, China \\ ${ }^{2}$ Departments of Radiation Oncology, Fujian Medical University Cancer Hospital, Fujian Cancer Hospital, Fuzhou, China \\ ${ }^{3}$ Department of Biochemistry and Molecular Biology, University of South China, Hengyang, China \\ ${ }^{4}$ Affiliated Xiamen First Hospital of Xiamen University, Xiamen, China \\ ${ }^{5}$ Xiamen Humanity Hospital, Xiamen, China \\ "These authors contributed equally to this work \\ Correspondence to: Yong Cai, email: caiyongfl@163.com \\ Keywords: tumor regression grade; two-week course; radiotherapy; rectal cancer; prognosis \\ Received: August 13,2017 Accepted: September 22, $2017 \quad$ Published: October 26, 2017 \\ Copyright: Li et al. This is an open-access article distributed under the terms of the Creative Commons Attribution License 3.0 \\ (CC BY 3.0), which permits unrestricted use, distribution, and reproduction in any medium, provided the original author and source \\ are credited.
}

\section{ABSTRACT}

Purpose: Studies concerning tumor regression grade (TRG) after two-week course of radiotherapy (RT) are limited. We tried to assess associations of TRG and outcomes in patients with locally advanced rectal cancer (LARC) treated with preoperative two-week course of RT.

Methods:356 consecutive LARC patients were retrospectively assessed. Patients with complete/intermediate (TRG1-3) and poor (TRG4-5) regressions were compared for overall survival (OS), disease-free survival (DFS) and metastasis-free survival (MFS).

Results: By univariate analysis, pretreatment and postoperative factors including TNM stages, ypT, ypN, surgical procedure, pathological grade, and TRG impacted survival outcomes. Complete/intermediate regressions (TRG1-3) had significantly improved survival outcomes compared with poor ones (TRG4-5) (5y-OS, $85.8 \%$ vs. $65.8 \%, P=0.001 ; 5 y-D F S, 76.0 \%$ vs. $53.7 \%, P<0.001 ; 5 y-M F S, 84.2 \%$ vs. $66.7 \%$, $P<0.001)$. Multivariate analysis showed that ypN $(P<0.001)$ and pathological grade $(P=0.018)$ were the most important independent prognostic factors for DFS. ypT $(P=0.014)$ and $y p N(P=0.001)$ were the independent prognostic factors for MFS. Meanwhile, ypT $(P=0.009)$, ypN $(P=0.001)$, surgical procedure $(p=0.001)$, and TRG $(p=0.019)$ were the independent prognostic factors for OS.

Conclusions:Complete/intermediate TRG regressions had a more favorable prognosis than the poor group. When treated with preoperative two-week course of RT; ypT, ypN, surgical procedure, and TRG seem to affect OS.

\section{INTRODUCTION}

Rectal cancer is the third most common malignancy worldwide [1]. Pre-operative radiotherapy (pre-RT) followed by total mesorectal excision (TME) has become the standard treatment sequence for locally advanced rectal cancer (LARC) [2, 3]. Clinical trials have largely revealed the best regimens for pre-RT. In China, a modified 
$30 \mathrm{~Gy} / 10$ fraction protocol for pre-RT was recommended by the Chinese Anti-Cancer Association in 2001 [4]. The modified protocol offers similar clinical outcomes to the reported long course RT regimen, providing an alternative to pre-RT regimens in China [5].

Tumor regression grade (TRG) after pre-RT was found to be significantly correlated with long term outcome in several studies [6-9]. However, TRG varies from complete absence of tumor cells to little or no regressive changes. Further studies suggested that complete response after pre-RT might improve survival [10-12]. Moreover, Suarez et al. [13] concluded that TRG might be a better prognostic factor than downstaging in predicting diseasefree survival after pre-chemoradiotherapy (CRT). Indeed, evaluation of TRG has been recommended as a routine procedure for rectal cancer [14].

While multiple reports have assessed the prognostic value of TRG in rectal cancer after long- or short-term preRT, studies evaluating TRG after 30-Gy protocol pre-RT are scarce. This study aimed to evaluate the association of TRG with long-term outcomes in patients with rectal cancer treated with $30 \mathrm{~Gy} / 10$ fraction pre-RT.

\section{RESULTS}

\section{Patient characteristics}

A total of 356 patients with mid-low (within 10 $\mathrm{cm}$ to the anal verge) rectal adenocarcinoma treated with pre-RT were assessed. The patient characteristics are summarized in Table 1. Median patient age was 58 years (range, 22 to 80 years). There were 205 (57.6\%) male and $151(42.4 \%)$ female patients. Among them, $216(60.7 \%)$ patients had low rectal cancer $(\leq$ within 5 $\mathrm{cm}$ to the anal verge) and $140(39.3 \%)$ presented with mid-rectal cancer $(5-10 \mathrm{~cm})$. Median distance to the anal verge was $5 \mathrm{~cm}$ (range, 1 to $10 \mathrm{~cm}$ ). Median time interval to surgery was 18 days, consisted of $162(45.5 \%)$ longer time inteval than 18 days and 194 (54.5\%) shorter than 18 days. Clinical stages before radiotherapy included stage I $(n=8,2.2 \%)$, stage II $(n=51,14.3 \%)$, stage III $(n=286$, $80.3 \%)$ and uncertain preoperative staging $(\mathrm{n}=11)$. Of the 356 patients, $262(70.2 \%)$ received postoperative adjuvant chemotherapy.

\section{Disease progression}

Median follow-up for all patients was 66.5 months (range, 5.1 to 131.7 months). Of the 356 analyzed patients, there were $86(24.2 \%)$ deaths, $38(10.7 \%)$ locoregional recurrences, and 77 (21.6\%) distant metastases. The rate of 5-year locoregional recurrences and distant metastases were $5.3 \%$ and $10.7 \%$. Locoregional recurrence cases included $19(5.3 \%, 19 / 356)$ patients with pelvic recurrence; $11(3.1 \%, 11 / 356)$ and $8(2.2 \%, 8 / 356)$ patients had pre-sacral and anastomotic recurrence, respectively.
Common distant metastasis sites included lung $(7.0 \%$, $25 / 356)$, liver $(6.5 \%, 23 / 356)$ and bone $(2.5 \%, 9 / 356)$.

\section{TRG and association with clinicopathologic factors}

Tumor regression grades were TRG $1(\mathrm{n}=17,4.8 \%)$, TRG $2(\mathrm{n}=142,39.9 \%)$, TRG $3(\mathrm{n}=22,6.2 \%)$, TRG 4 $(\mathrm{n}=13,3.6 \%)$, and TRG $5(\mathrm{n}=162,45.5 \%)$. To simplify the analysis, TRGs were combined into two groups, including complete/intermediate (TRG 1-3) and poor (TRG 4-5) regression groups. The associations of TRG with clinicopathologic factors are summarized in Table 2. TRG was significantly associated with age, clinical T stage, clinical N stage, ypT stage, ypN stage, American Joint Committee on Cancer (AJCC) cancer staging seventh edition, [15] pathologic grade, and lymphatic invasion. There were no significant differences between the two groups in patient sex and time interval to surgery. The relationship between TRG and $\mathrm{pN}$ was analyzed. Overall, 180 patients $(50.6 \%)$ with TRG1-3 were pN0, and one $(0.3 \%)$ was $\mathrm{pN}+$. Meanwhile, 17 patients $(4.8 \%)$ with TRG 4-5 were pN0 and the remaining $158(44.4 \%)$ were $\mathrm{pN}+(\mathrm{P}<0.001)$. Therefore, 99.4\% (180/181) of TRG $1-3$ patients achieved $\mathrm{pN} 0$, for only $9.7 \%$ (17/175) of TRG 4-5 cases.

\section{TRG is a prognostic factor for OS, DFS and MFS}

The TRG 1-3 and TRG 4-5 groups showed statistically significant differences in patient outcomes (Figure 1). Five-year OS rates were $85.8 \%(95 \% \mathrm{CI}=80.5$ $91.1 \%)$ and $65.8 \%(95 \% \mathrm{CI}=57.8-73.8 \%)$, respectively $(\mathrm{P}=0.001)$. Five-year DFS rates were $76.0 \%$ and $53.7 \%$ $(\mathrm{P}<0.001)$, and five-year MFS rates were $84.2 \%$ and $66.7 \%(\mathrm{P}<0.001)$, respectively. In addition, patients in the pathologic complete remission (pCR) and non-pCR groups showed five-year OS rates of $87.5 \%$ and $75.9 \%$, and five-year DFS rates of $87.5 \%$ and $64.2 \%$, respectively. The pCR group showed significantly improved five-year MFS compared with the non-pCR group (100\% vs. $74.4 \%$, $\mathrm{P}=0.045$ ) (Figure 2). Although not reaching statistical significance, the pCR group also showed a trend toward improved OS and DFS rates compared with the non-pCR group.

By univariate analysis, TRG was found to be significantly correlated with OS, DFS and MFS (Figure 1). As shown in Table 3, other factors significantly associated with DFS by univariate analysis included the ypT and ypN categories $(\mathrm{P}<0.001)$, TNM stage $(\mathrm{P}<0.001)$, and pathologic grade $(\mathrm{P}=0.002)$. Besides TRG, other factors in Table 4 that were significantly correlated with OS included the ypT and ypN categories $(\mathrm{P}<0.001)$, TNM stage $(\mathrm{P}<0.001)$, pathologic grade $(\mathrm{P}=0.006)$, and the surgical method ( $\mathrm{P}=0.007)$. Additionally, TRG $(\mathrm{P}<0.001)$, the ypT 
Table 1: Patient characteristics

\begin{tabular}{|c|c|}
\hline Characteristic & $\mathbf{N}(\%)$ \\
\hline \multicolumn{2}{|l|}{ Age (years) } \\
\hline$\leq 60$ & $205(57.6)$ \\
\hline$>60$ & $151(42.4)$ \\
\hline \multicolumn{2}{|l|}{ Sex } \\
\hline Male & $150(41.6)$ \\
\hline Female & $206(58.4)$ \\
\hline \multicolumn{2}{|c|}{ Distance to anal verge $(\mathrm{cm})$} \\
\hline $0-5$ & $216(60.7)$ \\
\hline$>5-10$ & $140(39.3)$ \\
\hline \multicolumn{2}{|l|}{ Pre-operate staging } \\
\hline I & $8(2.2)$ \\
\hline II & $51(14.3)$ \\
\hline III & $286(80.3)$ \\
\hline \multicolumn{2}{|l|}{ Surgery method } \\
\hline LAR & $234(65.7)$ \\
\hline $\mathrm{APR}+$ other & $122(34.3)$ \\
\hline \multicolumn{2}{|l|}{ Time interval to surgery } \\
\hline$\leq$ Median (18 days) & $162(45.5)$ \\
\hline$>$ Median & $194(54.5)$ \\
\hline \multicolumn{2}{|l|}{ Tumor regression grade } \\
\hline 1 & $17(4.8)$ \\
\hline 2 & $142(39.9)$ \\
\hline 3 & $22(6.2)$ \\
\hline 4 & $13(3.6)$ \\
\hline 5 & $162(45.5)$ \\
\hline
\end{tabular}

$A P R$ abdominoperineal resection; $L A R$ low anterior resection.

and ypN categories $(\mathrm{P}<0.001)$, TNM stage $(\mathrm{P}<0.001)$, and pathologic grade $(\mathrm{P}<0.001)$ also significantly affected MFS by univariate analysis (Table 5).

All significant factors in univariate analysis were entered in multivariate analysis for the respective end points. We found that $y p N(\mathrm{HR}=2.285,95 \% \mathrm{CI}=1.512-3.452$, $\mathrm{P}<0.001)$ and pathological grade $(\mathrm{HR}=1.620,95 \% \mathrm{CI}=1.087$ 2.415, $\mathrm{P}=0.018$ ) were the most important independent prognostic factors for DFS. ypT $(\mathrm{HR}=2.120,95 \% \mathrm{CI}=1.167$ $3.851, \mathrm{P}=0.014)$ and $\mathrm{ypN}(\mathrm{HR}=2.406,95 \% \mathrm{CI}=1.451-3.990$, $\mathrm{P}=0.001)$ were the independent prognostic factors for MFS. Meanwhile, ypT $(\mathrm{HR}=2.141,95 \% \mathrm{CI}=1.214-3.777, \mathrm{P}=0.009)$, $\mathrm{ypN}(\mathrm{HR}=7.774,95 \% \mathrm{CI}=2.360-25.601, \mathrm{P}=0.001)$, surgical procedure $(\mathrm{HR}=0.483,95 \% \mathrm{CI}=0.310-0.753, \mathrm{P}=0.001)$, and TRG $(\mathrm{HR}=1.647,95 \% \mathrm{CI}=1.076-2.492, \mathrm{P}=0.019)$ were the independent prognostic factors for OS. AS seen in Table 3-5.

\section{DISCUSSION}

Here, we report the largest cohort study assessing the associations of TRG with long-term outcomes in LARC patients treated with preoperative two-week course of radiotherapy. The results showed that complete/ intermediate TRG responders had a favorable prognosis. In addition, ypT, ypN, surgical procedure, and TRG seemed to affect OS.

The association of TRG after pre-RT with prognosis has been widely discussed for long-term or short-term RT regimens [16]. However, studies evaluating TRG in preoperative two-week course of radiotherapy are limited. We firstly reported the efficacy of a two-week course of pre-RT with 30 Gy in 10 fractions, and its associated clinical prognostic factors affecting OS and DFS in LARC [5]. Interestingly, patients treated with this modified regimen were shown to achieve similar OS to the reported long course RT regimen. After adding TRG to the longterm analysis, we further found that TRG might affect OS.

Besides the Mandard scoring system, several tumor regression systems have been recommended [1720]. The choice of tumor regression system remains controversial. Lossi et al. [20] used the Dworak system to evaluate the correlation between TRG and DFS, and found that good TRG could predict better DFS in LARC cases treated with long-course pre-CRT. Dworak et al [19] applied a 5-point scoring system of 0 to 4, ranging from no regression (TRG 0) to total regression (TRG 4), which is similar to Mandard's. Wheeler et al. [17] proposed another rectal cancer regression grade (RCRG) and modified Mandard classification into 3 points: RCRG 1 , either $\mathrm{pCR}$ or only microscopic foci of adenocarcinoma remaining; RCRG 2, marked fibrosis but macroscopic disease present; RCRG 3, poor response with little or no fibrosis, and abundant macroscopic disease. Rodel et al. [18] also suggested primary tumor regression to be grouped into three categories, from complete regression (Grade 1) to poor regression (Grade 3). In this study, application of Mandard system successfully identified two subgroups with different prognoses (5y-OS, 85.8\% vs. $65.8 \%, \mathrm{P}=0.001)$. Furthermore, TRG was one of the most important independent prognostic factors for OS.

The association of TRG with DFS has been demonstrated in previous reports. Losi et al. [20] demonstrated that TRG (Dworak grade) does not have a prognostic value for DFS in patients with residual cancer. Beddy et al. [21] applied a simplified Mandard system (3-point TRG) and found improved DFS in the combined group of patients with either complete- or near complete response versus the remaining patients. However, no difference in DFS was found between the 
Table 2: Association of TRG with clinicopathologic factors in 356 patients

\begin{tabular}{|c|c|c|c|}
\hline \multirow[t]{2}{*}{ Characteristic } & TRG 1-3 & TRG 4-5 & \multirow[t]{2}{*}{$\mathbf{P}$} \\
\hline & No. (\%) & No. (\%) & \\
\hline Age (years) & & & 0.002 \\
\hline$\leq 60$ & $90(25.3)$ & $116(32.6)$ & \\
\hline$>60$ & $91(25.6)$ & $59(16.6)$ & \\
\hline Sex & & & 0.306 \\
\hline Male & $109(30.6)$ & $96(27.0)$ & \\
\hline Female & $72(20.2)$ & 79 (22.2) & \\
\hline $\mathrm{cT}$ & & & 0.003 \\
\hline cT1-2 & $19(5.3)$ & $5(1.4)$ & \\
\hline cT3-4 & $154(43.3)$ & $167(46.9)$ & \\
\hline Unknown & $8(2.2)$ & $3(3.1)$ & \\
\hline $\mathrm{cN}$ & & & 0.001 \\
\hline No & $41(11.5)$ & $18(5.1)$ & \\
\hline $\mathrm{N} 1 / 2$ & $132(37.1)$ & $154(43.3)$ & \\
\hline Unknown & $8(2.2)$ & $3(0.8)$ & \\
\hline ypT category & & & $<0.001$ \\
\hline T0 & $17(4.8)$ & $2(0.6)$ & \\
\hline $\mathrm{T} 1$ & $17(4.8)$ & $3(0.8)$ & \\
\hline $\mathrm{T} 2$ & 71 (19.9) & $26(7.3)$ & \\
\hline $\mathrm{T} 3$ & $75(21.1)$ & $140(39.3)$ & \\
\hline $\mathrm{T} 4$ & $1(0.3)$ & $4(1.1)$ & \\
\hline ypN category & & & $<0.001$ \\
\hline N0 & $180(50.6)$ & $17(4.8)$ & \\
\hline $\mathrm{N}+$ & $1(0.3)$ & $158(44.4)$ & \\
\hline AJCC TNM stage & & & $<0.001$ \\
\hline $\mathrm{pCR}$ & $17(4.8)$ & $0(0)$ & \\
\hline I & 88 (24.7) & $4(1.1)$ & \\
\hline II & $75(21.1)$ & $13(3.7)$ & \\
\hline III & $1(0.3)$ & $158(44.7)$ & \\
\hline Pathologic grade & & & $<0.001$ \\
\hline High & $3(0.8)$ & $1(0.3)$ & \\
\hline Moderate & $132(37.1)$ & $108(30.3)$ & \\
\hline Low & $28(7.9)$ & $63(17.7)$ & \\
\hline Others & $18(5.1)$ & $3(0.8)$ & \\
\hline Time interval to surgery & & & 0.0651 \\
\hline$\leq$ Median (18day) & $121(34)$ & $113(31.7)$ & \\
\hline$>$ Median & $60(16.9)$ & $62(35.4)$ & \\
\hline Lymphatic invasion & & & $<0.001$ \\
\hline L0 & $170(47.8)$ & $142(39.9)$ & \\
\hline L1 & $11(3.1)$ & $33(9.3)$ & \\
\hline
\end{tabular}

$T R G$ tumor regression grade. 
TRG2 and TRG3 groups. Similarly, Bouzouirene et al. [6] and Rodel et al. [18] found better DFS with good tumor responders, as reflected by TRG categories in univariable analyses. However, after adjusting for other confounding variables, TRG showed no independent impact on DFS in multivariate analysis. In contrast, Vecchio et al. [16] and Dhadda et al. [22] both observed an association of
TRG with DFS in multivariable analyses. In addition, other reports with different TRG systems and multivariate analyses failed to demonstrate the prognostic value of TRG for DFS [18, 23-25]. In the current analysis, however, five TRG categories were combined into two different groups, including complete/intermediate (TRG 1-3) and poor (TRG 4-5) responders. The responder
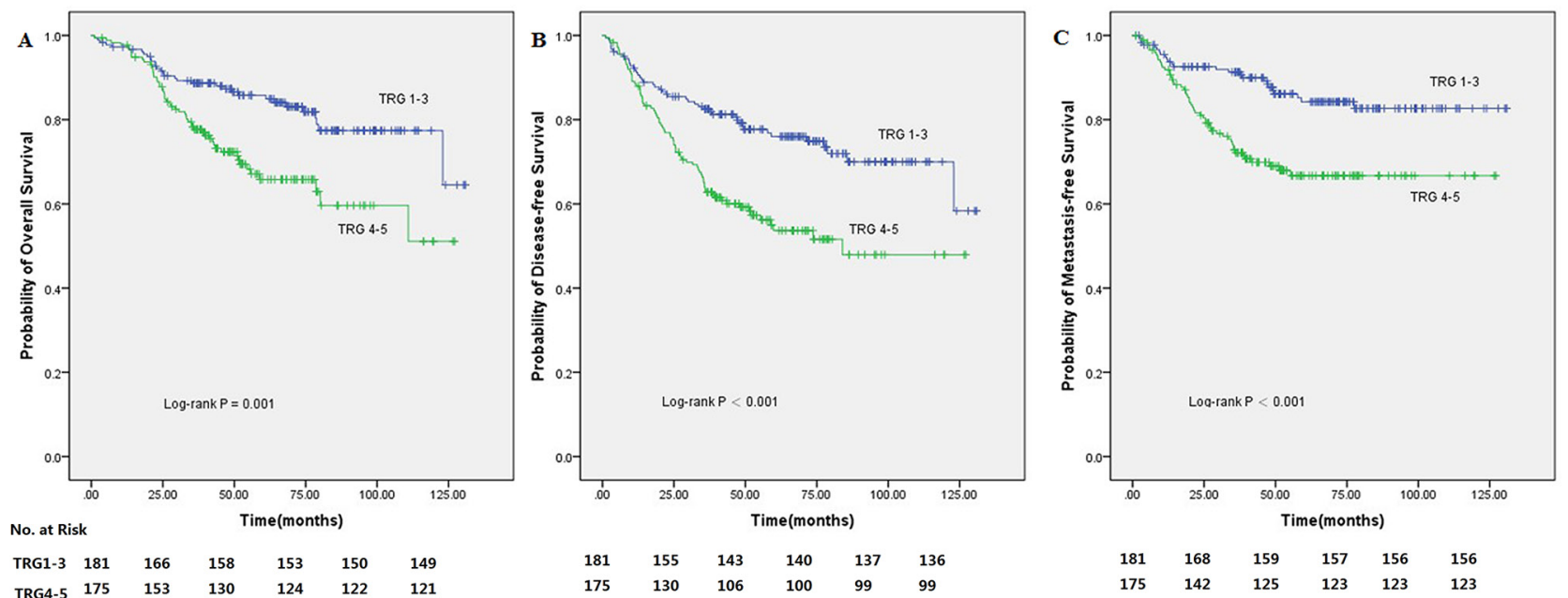

Figure 1: Kaplan-Meier analysis of 356 rectal cancer patients treated with preoperative radiotherapy (30 Gy in 10 fractions) followed by surgery with curative intent according to tumor regression grade (TRG1-3/TRG4-5) showed statistically significant difference. (A) The 5-year OS of patients with TRG1-3 versus TRG4-5. (B) The 5-year DFS of patients with TRG1-3 versus TRG4-5. (C) The 5-year MFS of patients with TRG1-3 versus TRG4-5.

A

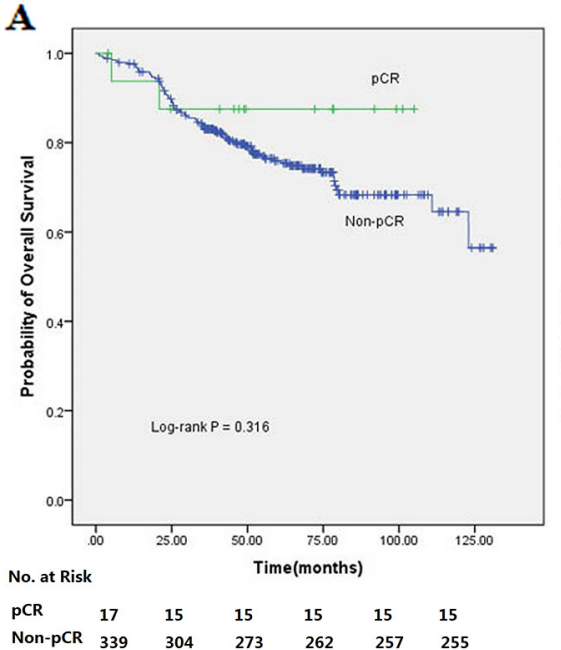

B

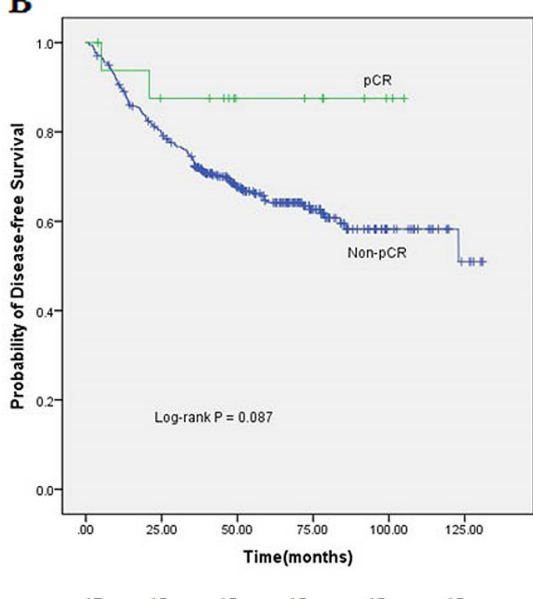

$\begin{array}{llllll}17 & 15 & 15 & 15 & 15 & 15 \\ 339 & 270 & 234 & 225 & 221 & 220\end{array}$

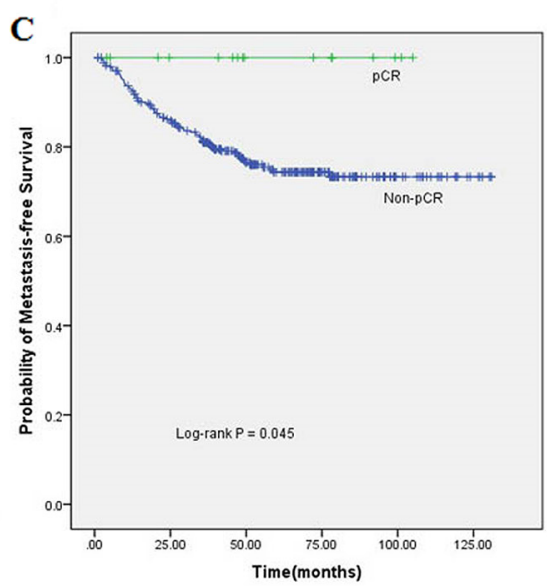

$\begin{array}{llllll}17 & 17 & 17 & 17 & 17 & 17 \\ 339 & 293 & 267 & 263 & 262 & 262\end{array}$

Figure 2: Kaplan-Meier analysis of 356 rectal cancer patients treated with preoperative radiotherapy (30 Gy in 10 fractions) followed by surgery with curative intent according to pCR (pCR/non-pCR). (A) The 5-year OS of patients with pCR versus non-pCR. (B) The 5-year DFS of patients with pCR versus non-pCR. (C) The 5-year MFS of patients with pCR versus nonpCR. 
Table 3: Cox regression for disease-free survival analysis

\begin{tabular}{|c|c|c|c|c|c|c|}
\hline & \multicolumn{3}{|c|}{ Univariate } & \multicolumn{3}{|c|}{ Multivariate } \\
\hline & HR & $95 \% \mathrm{CI}$ & $\mathbf{P}$ & HR & $95 \% \mathrm{CI}$ & $\mathbf{P}$ \\
\hline Age & 0.745 & $0.498-1.116$ & 0.154 & & & \\
\hline Sex & 0.871 & $0.590-1.286$ & 0.487 & & & \\
\hline $\mathrm{cT}$ & 2.100 & $0.772-5.711$ & 0.146 & & & \\
\hline $\mathrm{cN}$ & 1.440 & $0.804-2.581$ & 0.220 & & & \\
\hline Distance to anal verge $(\mathrm{cm})$ & 1.137 & $0.766-1.686$ & 0.525 & & & \\
\hline ypT & 2.731 & $1.701-4.385$ & $<0.001$ & 1.636 & $0.879-3.047$ & 0.121 \\
\hline ypN & 2.671 & $1.780-4.009$ & $<0.001$ & 2.285 & $1.512-3.452$ & $<0.001$ \\
\hline AJCC TNM stage & 1.862 & $1.447-2.397$ & $<0.001$ & 1.076 & $0.545-2.125$ & 0.833 \\
\hline TRG 1-3 vs. TRG 4-5 & 2.259 & $1.501-3.399$ & $<0.001$ & 0.446 & $0.139-1.434$ & 0.175 \\
\hline Pathologic grade & 1.889 & $1.275-2.798$ & 0.002 & 1.620 & $1.087-2.415$ & 0.018 \\
\hline Surgery method & 1.228 & $0.818-1.844$ & 0.322 & & & \\
\hline Time interval to surgery & 1.428 & $0.968-2.106$ & 0.073 & & & \\
\hline Lymphatic invasion & 1.337 & $0.784-2.280$ & 0.287 & & & \\
\hline Adjuvant Chemotherapy & 1.410 & $0.898-2.216$ & 0.136 & & & \\
\hline
\end{tabular}

$T R G$ tumor regression grade.

Table 4: Cox regression for overall survival analysis

\begin{tabular}{|c|c|c|c|c|c|c|}
\hline & \multicolumn{3}{|c|}{ Univariate } & \multicolumn{3}{|c|}{ Multivariate } \\
\hline & HR & $95 \% \mathrm{CI}$ & $\mathbf{P}$ & HR & $95 \% \mathrm{CI}$ & $\mathbf{P}$ \\
\hline Age & 0.957 & $0.623-1.469$ & 0.841 & & & \\
\hline Sex & 1.118 & $0.727-1.720$ & 0.612 & & & \\
\hline $\mathrm{cT}$ & 2.366 & $0.747-7.496$ & 0.143 & & & \\
\hline $\mathrm{cN}$ & 1.508 & $0.798-2.853$ & 0.206 & & & \\
\hline $\begin{array}{l}\text { Distance to anal } \\
\text { verge }(\mathrm{cm})\end{array}$ & 0.764 & $0.488-1.197$ & 0.240 & & & \\
\hline ypT & 2.503 & $1.512-4.144$ & $<0.001$ & 2.141 & $1.214-3.777$ & 0.009 \\
\hline ypN & 2.721 & $1.746-4.240$ & $<0.001$ & 7.774 & $2.360-25.601$ & 0.001 \\
\hline $\begin{array}{l}\text { AJCC TNM } \\
\text { stage }\end{array}$ & 1.825 & $1.390-2.397$ & $<0.001$ & 1.086 & $0.482-2.444$ & 0.843 \\
\hline $\begin{array}{l}\text { TRG } 1-3 \text { vs. } \\
\text { TRG 4-5 }\end{array}$ & 2.143 & $1.378-3.333$ & 0.001 & 1.647 & $1.076-2.492$ & 0.019 \\
\hline Pathologic grade & 1.849 & $1.192-2.867$ & 0.006 & 1.221 & $0.833-1.788$ & 0.307 \\
\hline Surgery method & 0.744 & $0.601-0.922$ & 0.007 & 0.483 & $0.310-0.753$ & 0.001 \\
\hline $\begin{array}{l}\text { Time interval to } \\
\text { surgery }\end{array}$ & 1.443 & $0.942-2.210$ & 0.092 & & & \\
\hline $\begin{array}{l}\text { Lymphatic } \\
\text { invasion }\end{array}$ & 1.482 & $0.848-2.591$ & 0.167 & & & \\
\hline $\begin{array}{l}\text { Adjuvant } \\
\text { Chemotherapy }\end{array}$ & 0.709 & $0.451-1.114$ & 0.136 & & & \\
\hline
\end{tabular}

$T R G$ tumor regression grade. 
Table 5: Cox regression for metastasis-free survival analysis

\begin{tabular}{|c|c|c|c|c|c|c|}
\hline & \multicolumn{3}{|c|}{ Univariate } & \multicolumn{3}{|c|}{ Multivariate } \\
\hline & HR & $95 \% \mathrm{CI}$ & $\mathbf{P}$ & HR & $95 \% \mathrm{CI}$ & $\mathbf{P}$ \\
\hline Age & 0.714 & $0.447-1.141$ & 0.159 & & & \\
\hline Sex & 1.321 & $0.845-2.065$ & 0.222 & & & \\
\hline $\mathrm{cT}$ & 2.084 & $0.657-6.616$ & 0.213 & & & \\
\hline $\mathrm{cN}$ & 1.406 & $0.722-2.736$ & 0.316 & & & \\
\hline $\begin{array}{l}\text { Distance to anal } \\
\text { verge }(\mathrm{cm})\end{array}$ & 1.028 & $0.906-1.166$ & 0.673 & & & \\
\hline ypT & 2.954 & $1.679-5.197$ & $<0.001$ & 2.120 & $1.167-3.851$ & 0.014 \\
\hline ypN & 3.060 & $1.896-4.939$ & $<0.001$ & 2.406 & $1.451-3.990$ & 0.001 \\
\hline AJCC TNM stage & 1.985 & $1.467-2.686$ & $<0.001$ & 0.862 & $0.355-2.091$ & 0.084 \\
\hline $\begin{array}{l}\text { TRG } 1-3 \text { vs. TRG } \\
4-5\end{array}$ & 2.458 & $1.523-3.966$ & $<0.001$ & 0.336 & $0.085-1.326$ & 0.129 \\
\hline Pathologic grade & 1.108 & $0.781-1.573$ & 0.564 & & & \\
\hline Surgery method & 0.999 & $0.617-1.619$ & 0.997 & & & \\
\hline $\begin{array}{l}\text { Time interval to } \\
\text { surgery }\end{array}$ & 1.234 & $0.789-1.930$ & 0.357 & & & \\
\hline $\begin{array}{l}\text { Lymphatic } \\
\text { invasion }\end{array}$ & 1.601 & $0.897-2.857$ & 0.111 & & & \\
\hline $\begin{array}{l}\text { Adjuvant } \\
\text { Chemotherapy }\end{array}$ & 0.854 & $0.517-1.412$ & 0.539 & & & \\
\hline
\end{tabular}

$T R G$ tumor regression grade.

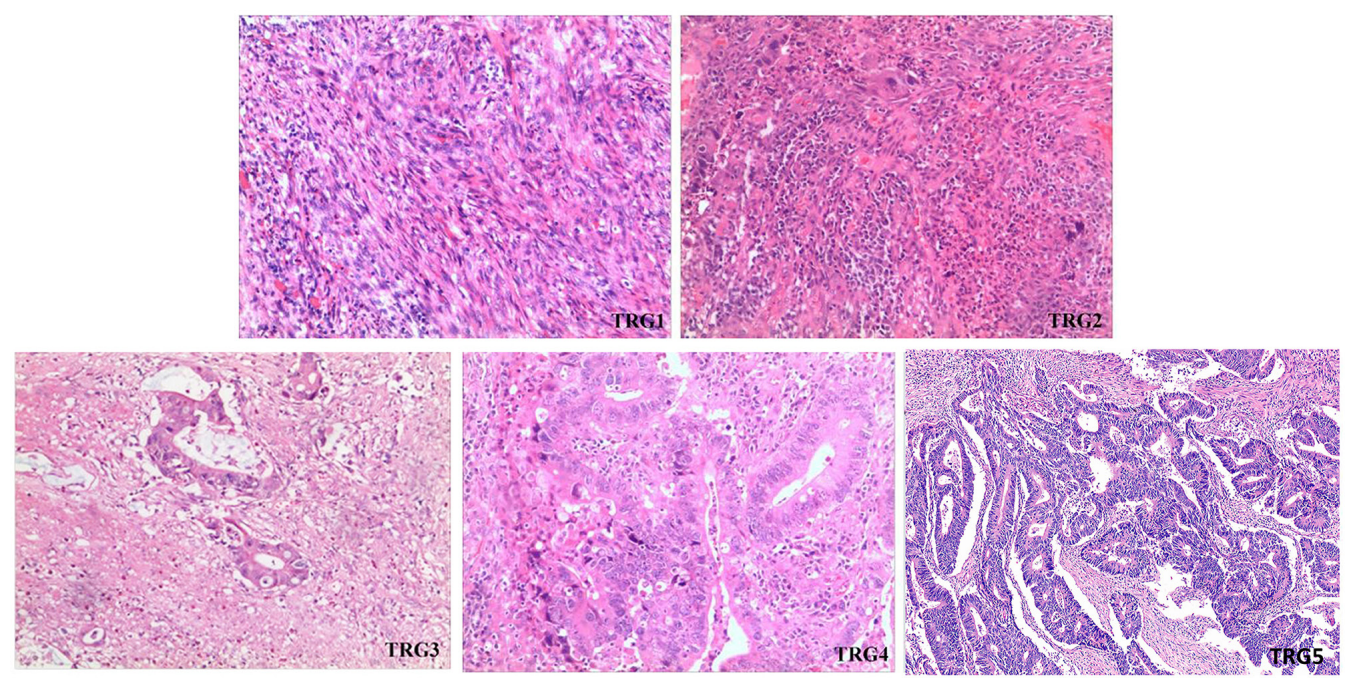

Figure 3: Tumor regression grading of rectal tumors in patients treated preoperatively with radiotherapy. (TRG1) complete response with no residual cancer or fibrosis extending through the wall; (TRG2) presence of residual cancer cells scattered through the fibrosis; (TRG3) increased number of residual cancer cells, with fibrosis predominating; (TRG4) residual cancer outgrowing the fibrosis; (TRG5) absence of regressive changes. 
groups showed significantly different DFS rates (5y-DFS, $76.0 \%$ vs. $53.7 \%, \mathrm{P}<0.001)$.

The positive association between TRG and the risk of nodal disease was described by univariable analysis in this study and others $[6,16,18,21,26]$. As shown above, complete/intermediate tumor regression (TRG 1-3) was associated with improved disease control in lymph nodes (ypN positive, $0.3 \%$ ), which might account for DFS. Patients with poor tumor regression (TRG 4-5) had a higher risk of lymph node involvement (ypN positive, $44.4 \%$ ) and an unfavorable outcome. In addition, histopathologic factors, especially the $\mathrm{N}$ stage, remained the most important prognostic factors in the multivariate model, corroborating previous studies $[18,27]$. After preCRT, positive lymph nodes could both indicate primary cancer aggressiveness and resistance to CRT. Therefore, patients with ypN positive would have an unfavorable prognosis irrespective of the TRG.

This study demonstrated that tumor regression after pre-RT was closely associated with pathological T and $\mathrm{N}$ stages. As shown above, the majority of poorly responding tumors contributed to nodal metastasis, indicating that TRG could be an effective supplement to the TNM classification. As a prognostic factor after preRT, TRG might also guide clinical decision making for further postoperative adjuvant chemotherapy in different subgroups of patients. Further prospective clinical trials focusing on the predictive value of TRG for adjuvant chemotherapy are warranted.

As a single-center study, some limitations should be mentioned. First, this was a retrospective study, which might have selection bias. Sample size in some TRG subgroups was relatively small; this might affect the reliability of the findings. In addition, TRG requires surgery and can only be used after pathology. Several studies had investigated the value of other indicators such as dynamic contrast enhanced magnetic resonance imaging (DCE-MRI) or blood count levels for treatment response assessment [28-31]. Therefore, further studies are necessary to explore tumor response to preoperative twoweek course of radiotherapy by combination of TRG and other indicators.

\section{MATERIALS AND METHODS}

\section{Patients}

A total of 356 LARC patients who underwent a 30-Gy pre-RT followed by curative surgery in our institution from September 2002 to October 2010 were analyzed in this study. Eligible patients were selected according to the following criteria: (1) pathological diagnosis of adenocarcinoma; (2) middle or low rectum (within $10 \mathrm{~cm}$ of the anal verge) involvement, (3) locally advanced disease (clinically T3/T4, or any $\mathrm{T}$ category and $\mathrm{N}$ positive) revealed by endorectal ultrasound (EUS) and MRI, a few patients presenting with T1/T2N0 tumors located within $5 \mathrm{~cm}$ from the anal verge could also be included for the purpose of sphincterpreserving. (4) no history of other malignant diseases, and (5) no distant metastasis. Exclusion criteria were: (1) familial adenomatous polyposis; (2) upper rectal cancer; (3) a history of other malignancies within 5 years. Pretreatment evaluation included a complete history, physical examination, complete laboratory tests, and preoperative staging. The study was approved by the Ethics Committee of Beijing Cancer Hospital, Beijing, China. And all the eligible patients signed the informed consent before treatment.

\section{Treatment}

The RT was delivered in 10 fractions of 3 Gy, five times per week over 2 weeks. This dose was delivered using a 3-field technique, with the patient in the prone position. The clinical target volume included the primary tumor, anorectum, and mesorectal, perirectal, and internal iliac nodes, but excluding the external and common iliac nodes. The delineations of the 3 pelvic fields were described previously $[32,33]$.

All the patients underwent total mesorectal excision (TME) 2 weeks after pre-RT completion. The choice between abdominoperineal resection and anterior resection was left to the discretion of the attending surgeon. The decision for adjuvant chemotherapy was left to medical oncologists.

\section{Tumor regression grade}

All resection specimens were assessed independently by two pathologists, who were aware of the patient's history but blinded to clinical stage. The histology of all surgical specimens was classified according to the Mandard TRG system [34]: TRG1, complete response with no residual cancer or fibrosis extending through the wall; TRG2, presence of residual cancer cells scattered through the fibrosis; TRG3, increased number of residual cancer cells, with fibrosis predominating; TRG4, residual cancer outgrowing the fibrosis; TRG5, absence of regressive changes. As shown in Figure 3.

\section{Follow-up}

Patients were routinely followed up every 3 months for the first 2 years, every 6 months for subsequent 3 years, and annually thereafter. Follow-up laboratory tests included complete blood count, blood chemical analysis, and carcinoembryonic antigen (CEA) detection. Chest $\mathrm{x}$-ray, abdominal ultrasound or CT, and CT of the pelvis were performed at each follow-up visit.

\section{Statistical analysis}

The primary endpoints of this study included overall survival (OS), disease-free survival (DFS) and 
metastasis-free survival (MFS). Categorical variables were compared by Pearson $\chi^{2}$ test. Survival curves were generated by the Kaplan-Meier method, and compared using the log-rank test. Two-tailed $\mathrm{P}<0.05$ was considered statistically significant. The Cox proportional hazards model was used for multivariate analysis. Statistical analyses were performed with SPSS version 22.0.

\section{CONCLUSIONS}

In summary, TRG appears to be a good prognostic factor for patients treated with preoperative two-week course of radiotherapy. More prospective trials are required to validate these findings and assess TRG for its promising value in clinical decision making for adjuvant therapy.

\section{Ethical Approval}

The study was approved by the Ethics Committee of Beijing Cancer Hospital, Beijing, China. All procedures performed in studies involving human participants were in accordance with the ethical standards of the institutional and/or national research committee and with the 1964 Helsinki declaration and its later amendments or comparable ethical standards.

\section{CONFLICTS OF INTEREST}

The authors declare no conflicts of interest.

\section{FUNDING}

This study was funded by the Fujian Province Natural Science Foundation (No. 2016J01437 and 2017J01260), the Fujian Medical Innovation Project (No. 2015-CX-8), and Key Laboratory of Carcinogenesis and Translational Research (Ministry of Education/Beijing), Peking University Cancer Hospital \& Institute (2017 Open Project-9).

\section{REFERENCES}

1. Siegel R, Ward E, Brawley O, Jemal A. Cancer statistics, 2011: the impact of eliminating socioeconomic and racial disparities on premature cancer deaths. CA Cancer J Clin. 2011; 61: 212-36. https://doi.org/10.3322/caac.20121.

2. Fleming FJ, Pahlman L, Monson JR. Neoadjuvant therapy in rectal cancer. Dis Colon Rectum. 2011; 54: 901-12. https://doi.org/10.1007/DCR.0b013e31820eeb37.

3. Minsky BD, Rodel C, Valentini V. Short-course radiation versus long-course chemoradiation for rectal cancer. J Natl Compr Canc Netw. 2012; 10: 1223-31. https://doi. org/10.6004/jncen.2012.0129.

4. Zhan $\mathrm{T}, \mathrm{Gu} \mathrm{J}, \mathrm{Li} \mathrm{M}, \mathrm{Du} \mathrm{C}$. Intermediate-fraction neoadjuvant radiotherapy for rectal cancer. Dis Colon
Rectum. 2013; 56: 422-32. https://doi.org/10.1097/ DCR.0b013e31828576c6.

5. Zhu XG, Li JL, Li XF, Li YH, Ni QY, Wang L, Zhang SW, Gu J, Cai Y, Lin C. Two-week Course of Preoperative Radiotherapy for Locally Advanced Rectal Adenocarcinoma: 8 Years' Experience in a Single Institute. Am J Clin Oncol. 2017; 40: 266-73. https://doi.org/10.1097/ coc.037465R1037465R10142.

6. Bouzourene H, Bosman FT, Seelentag W, Matter M, Coucke P. Importance of tumor regression assessment in predicting the outcome in patients with locally advanced rectal carcinoma who are treated with preoperative radiotherapy. Cancer. 2002; 94: 1121-30. https://doi.org/10.1002/cncr.10327.

7. Bozzetti F, Andreola S, Baratti D, Mariani L, Stani SC, Valvo F, Spinelli P. Preoperative chemoradiation in patients with resectable rectal cancer: results on tumor response. Ann Surg Oncol. 2002; 9: 444-9. https://doi.org/10.1007/ BF02557266.

8. Horn A, Morild I, Dahl O. Tumour shrinkage and down staging after preoperative radiation of rectal adenocarcinomas. Radiother Oncol. 1990; 18: 19-28. https://doi.org/10.1016/0167-8140(90)90019-S.

9. Reerink O, Verschueren RC, Szabo BG, Hospers GA, Mulder NH. A favourable pathological stage after neoadjuvant radiochemotherapy in patients with initially irresectable rectal cancer correlates with a favourable prognosis. Eur J Cancer. 2003; 39: 192-5. https://doi. org/10.1016/S0959-8049(02)00557-9.

10. Zorcolo L, Rosman AS, Restivo A, Pisano M, Nigri GR, Fancellu A, Melis M. Complete pathologic response after combined modality treatment for rectal cancer and longterm survival: a meta-analysis. Ann Surg Oncol. 2012; 19: 2822-32. https://doi.org/10.1245/s10434-011-2209-y.

11. Martin ST, Heneghan HM, Winter DC. Systematic review and meta-analysis of outcomes following pathological complete response to neoadjuvant chemoradiotherapy for rectal cancer. Br J Surg. 2012; 99: 918-28. https://doi. org/10.1002/bjs.8702.

12. Maas M, Nelemans PJ, Valentini V, Das P, Rodel C, Kuo LJ, Calvo FA, Garcia-Aguilar J, Glynne-Jones R, Haustermans K, Mohiuddin M, Pucciarelli S, Small W Jr, et al. Longterm outcome in patients with a pathological complete response after chemoradiation for rectal cancer: a pooled analysis of individual patient data. Lancet Oncol. 2010; 11: 835-44. https://doi.org/10.1016/s1470-2045(10)70172-8.

13. Suarez J, Vera R, Balen E, Gomez M, Arias F, Lera JM, Herrera J, Zazpe C. Pathologic response assessed by Mandard grade is a better prognostic factor than down staging for disease-free survival after preoperative radiochemotherapy for advanced rectal cancer. Colorectal Dis. 2008; 10: 563-8. https://doi.org/10.1111/j.1463-1318.2007.01424.x.

14. Colon and rectum cancer staging. In: AJCC staging manual, 7th edition, December 2009. https://cancerstaging.org/ references-tools/quickreferences/Documents/ColonMedium. pdf. 
15. Edge SB, Compton CC. The American Joint Committee on Cancer: the 7th edition of the AJCC cancer staging manual and the future of TNM. Ann Surg Oncol. 2010; 17: 1471-4. https://doi.org/10.1245/s10434-010-0985-4.

16. Vecchio FM, Valentini V, Minsky BD, Padula GD, Venkatraman ES, Balducci M, Micciche F, Ricci R, Morganti AG, Gambacorta MA, Maurizi F, Coco C. The relationship of pathologic tumor regression grade (TRG) and outcomes after preoperative therapy in rectal cancer. Int J Radiat Oncol Biol Phys. 2005; 62: 752-60. https://doi. org/10.1016/j.ijrobp.2004.11.017.

17. Wheeler JM, Warren BF, Mortensen NJ, Ekanyaka N, Kulacoglu H, Jones AC, George BD, Kettlewell MG. Quantification of histologic regression of rectal cancer after irradiation: a proposal for a modified staging system. Dis Colon Rectum. 2002; 45: 1051-6. https://doi.org/10.1007/ s10350-004-6359-X.

18. Rodel C, Martus P, Papadoupolos T, Fuzesi L, Klimpfinger M, Fietkau R, Liersch T, Hohenberger W, Raab R, Sauer R, Wittekind C. Prognostic significance of tumor regression after preoperative chemoradiotherapy for rectal cancer. J Clin Oncol. 2005; 23: 8688-96. https://doi.org/10.1200/ jco.2005.02.1329.

19. Dworak O, Keilholz L, Hoffmann A. Pathological features of rectal cancer after preoperative radiochemotherapy. Int J Colorectal Dis. 1997; 12: 19-23. https://doi.org/10.1007/ s003840050072.

20. Losi L, Luppi G, Gavioli M, Iachetta F, Bertolini F, D’Amico R, Jovic G, Bertoni F, Falchi AM, Conte PF. Prognostic value of Dworak grade of regression (GR) in patients with rectal carcinoma treated with preoperative radiochemotherapy. Int J Colorectal Dis. 2006; 21: 645-51. https://doi.org/10.1007/s00384-005-0061-x.

21. Beddy D, Hyland JM, Winter DC, Lim C, White A, Moriarty M, Armstrong J, Fennelly D, Gibbons D, Sheahan K. A simplified tumor regression grade correlates with survival in locally advanced rectal carcinoma treated with neoadjuvant chemoradiotherapy. Ann Surg Oncol. 2008; 15: 3471-7. https://doi.org/10.1245/s10434-008-0149-y.

22. Dhadda AS, Dickinson P, Zaitoun AM, Gandhi N, Bessell EM. Prognostic importance of Mandard tumour regression grade following pre-operative chemo/radiotherapy for locally advanced rectal cancer. Eur J Cancer. 2011; 47: 1138-45. https://doi.org/10.1016/j.ejca.2010.12.006.

23. Bujko K, Kolodziejczyk M, Nasierowska-Guttmejer A, Michalski W, Kepka L, Chmielik E, Wojnar A, Chwalinski M. Tumour regression grading in patients with residual rectal cancer after preoperative chemoradiation. Radiother Oncol. 2010; 95: 298-302. https://doi.org/10.1016/j.radonc.2010.04.005.

24. Machiels JP, Aydin S, Bonny MA, Hammouch F, Sempoux C. What is the best way to predict disease-free survival after preoperative radiochemotherapy for rectal cancer patients: tumor regression grading, nodal status, or circumferential resection margin invasion? J Clin Oncol. 2006; 24: 1319; author reply 20-1. https://doi.org/10.1200/jco.2005.05.0963.
25. Lindebjerg J, Spindler KL, Ploen J, Jakobsen A. The prognostic value of lymph node metastases and tumour regression grade in rectal cancer patients treated with long-course preoperative chemoradiotherapy. Colorectal Dis. 2009; 11: 264-9. https://doi. org/10.1111/j.1463-1318.2008.01599.x.

26. Berho M, Oviedo M, Stone E, Chen C, Nogueras J, Weiss E, Sands D, Wexner S. The correlation between tumour regression grade and lymph node status after chemoradiation in rectal cancer. Colorectal Dis. 2009; 11: 254-8. https://doi.org/10.1111/j.1463-1318.2008.01597.x.

27. Chapet O, Romestaing P, Mornex F, Souquet JC, Favrel V, Ardiet JM, d'Hombres A, Gerard JP. Preoperative radiotherapy for rectal adenocarcinoma: Which are strong prognostic factors? Int J Radiat Oncol Biol Phys. 2005; 61: 1371-7. https://doi.org/10.1016/j.ijrobp.2004.08.022.

28. Petrillo A, Fusco R, Petrillo M, Granata V, Delrio P, Bianco F, Pecori B, Botti G, Tatangelo F, Caraco C, Aloj L, Avallone A, Lastoria S. Standardized Index of Shape (DCE-MRI) and Standardized Uptake Value (PET/CT): Two quantitative approaches to discriminate chemoradiotherapy locally advanced rectal cancer responders under a functional profile. Oncotarget. 2017; 8: 8143-53. https://doi.org/10.18632/oncotarget.14106.

29. Zhang J, Zhang HY, Li J, Shao XY, Zhang CX. The elevated NLR, PLR and PLT May predict the prognosis of patients with colorectal cancer: a systematic review and metaanalysis. Oncotarget. 2017;8:68837-68846. https://doi. org/10.18632/oncotarget.18575.

30. Santos MD, Silva C, Rocha A, Nogueira C, Castro-Pocas F, Araujo A, Matos E, Pereira C, Medeiros R, Lopes C. Predictive clinical model of tumor response after chemoradiation in rectal cancer. Oncotarget. 2017;8:5813358151. https://doi.org/10.18632/oncotarget.19651.

31. Dreyer SB, Powell AGMT, McSorley ST, Waterston A, Going JJ, Edwards J, McMillan DC, Horgan PG. The Pretreatment Systemic Inflammatory Response is an Important Determinant of Poor Pathologic Response for Patients Undergoing Neoadjuvant Therapy for Rectal Cancer. Annals of Surgical Oncology. 2017; 24: 1295-303. https://doi.org/10.1245/s10434-016-5684-3.

32. Gay HA, Barthold HJ, O'Meara E, Bosch WR, El Naqa I, Al-Lozi R, Rosenthal SA, Lawton C, Lee WR, Sandler H, Zietman A, Myerson R, Dawson LA, et al. Pelvic normal tissue contouring guidelines for radiation therapy: a Radiation Therapy Oncology Group consensus panel atlas. Int J Radiat Oncol Biol Phys. 2012; 83: e353-62. https://doi. org/10.1016/j.ijrobp.2012.01.023.

33. Myerson RJ, Garofalo MC, El Naqa I, Abrams RA, Apte A, Bosch WR, Das P, Gunderson LL, Hong TS, Kim JJ, Willett CG, Kachnic LA. Elective clinical target volumes for conformal therapy in anorectal cancer: a radiation therapy oncology group consensus panel contouring atlas. Int J Radiat Oncol Biol Phys. 2009; 74: 824-30. https://doi. org/10.1016/j.ijrobp.2008.08.070. 
34. Mandard AM, Dalibard F, Mandard JC, Marnay J, HenryAmar M, Petiot JF, Roussel A, Jacob JH, Segol P, Samama G. Pathologic assessment of tumor regression after preoperative chemoradiotherapy of esophageal carcinoma. Clinicopathologic correlations. Cancer. 1994; 73: 2680-6. https://doi. org/10.1002/1097-0142(19940601)73:11<2680::AIDCNCR2820731105>3.0.CO;2-C. 